\title{
DAS SEMENTES AOS FRUTOS: POR UMA CULTURA DA CONCILIAÇÃO E MEDIAÇÃO NO SEMIÁRIDO POTIGUAR.
}

\author{
SEEDS TO FRUIT : FOR A CULTURE OF CONCILIATION AND MEDIATION IN \\ SEMIARID POTIGUAR.
}

\author{
${ }^{1}$ José Albenes Bezerra Júnior
}

\section{RESUMO}

O presente artigo pretende abordar a cultura judiciarista como um fator responsável pela ineficiência na solução dos conflitos. Para isso, visa analisar os novos instrumentos legais, resolução 125 do CNJ e o novo código processual civil, bem como discutir o papel dos cursos de Direito nesses casos. Além disso, pretende abordar o projeto "Das sementes aos frutos", desenvolvido pelo curso de Direito da Universidade Federal Rural do Semiárido - UFERSA, atividade que visa, através de pesquisas e práticas, o fomento à cultura da mediação e da conciliação, colhendo, assim, os frutos compatíveis com as sementes plantadas.

Palavras-chave: Conciliação, Cultura, Mediação, Semiárido

\begin{abstract}
This article aims to address the judiciarista culture as a factor responsible for the inefficiency in solving conflicts. For this, it aims to analyze the new legal instruments, Resolution 125 of the CNJ and the new civil procedure code, as well as discuss the role of law schools in these cases. It also aims to address the project "From seed to fruit", developed by the Law School of the Federal Rural University of Semi-Arid - UFERSA, activity which aims, through research and practices, fostering the culture of mediation and conciliation, collecting thus the fruits compatible with the seeds planted.
\end{abstract}

Keywords: Conciliation, Culture, Mediation, Semiarid

\footnotetext{
${ }^{1}$ Doutorando em Direito pela Universidade de Brasília - UNB, Distrito Federal, (Brasil). Professor da Universidade Federal Rural do Semi-Árido - UFERSA, Mossoró, Rio Grande do Norte. E-mail: jalbenes@hotmail.com
} 


\section{INTRODUÇÃO: SERÁ QUE PLANTAMOS AS SEMENTES CERTAS?}

O sentido contemporâneo de acesso à justiça, em decorrência dos variados métodos de solução de conflitos, não permite mais uma exata identificação do serviço judiciário como única e exclusiva ferramenta de solução das lides. A cultura judiciarista traz, como perverso efeito colateral, a (falsa) percepção de que todo e qualquer prejuízo temido ou sofrido tem que ser necessariamente reparado por uma demanda judicial. Isso só potencializa a deficiência na solução dos conflitos, além de evidenciar uma maior resistência à utilização dos outros meios de resolução de litígios.

Observa-se, com isso, uma necessidade de compreensão do que se deva entender por acesso à justiça, expressão que acabou perdendo seu real significado e gerando uma externalidade negativa: $\mathrm{O}$ fomento à cultura demandista, sobrecarregando o Judiciário e desservindo o cidadão na medida em que desestimula a busca pela mediação de conflitos.

O conceito de acesso à justiça tem sofrido uma transformação importante, correspondente a uma mudança no estudo e ensino do processo civil. O enfoque sobre o acesso também caracteriza crescentemente o estudo e a necessidade de certas rediscussões (CAPPELLETTI, GARTH, 2002, p.12).

A concepção de um serviço de distribuição de justiça monopolizado pelo Estado, acompanhado de uma concepção incondicionada de prestação judiciária, deve ser gradualmente afastada. O monopólio estatal de distribuição da Justiça não guarda aderência à realidade atual, devendo ser devidamente revistado e contextualizado para se compatibilizar com as necessidades e interesses emergentes na contemporânea sociedade.

Assim, diante de tal realidade, surgiu a necessidade e repensar o conceito para o que se entende por "acesso à justiça", sendo que tal consideração deve avaliar alguns pontos, quais sejam: a jurisdição não é o único meio de solução de conflitos; que um processo caro, lento, custoso, não permitirá que pessoas de menor poder aquisitivo consigam intentar demandas e defender seus interesses.

O acesso à justiça precisa estar mais ligado à satisfação do usuário, ou jurisdicionado, com o resultado final do processo de resolução de conflito do que com o mero acesso ao Poder Judiciário, a uma relação jurídica processual ou ao ordenamento jurídico material aplicado ao caso concreto. 
Recentemente, foram criados mecanismos de fomento à cultura da pacificação. Merecem destaque a criação da Resolução 125 do Conselho Nacional de Justiça, de 2010; e, recentemente, a aprovação e promulgação no novo Código Processual Civil (Lei n. 13.105/2005), que passa a estabeler, em seus dispositivos iniciais, que "a conciliação, a mediação e outros métodos de solução consensual de conflitos deverão ser estimulados por juízes, advogados, defensores públicos e membros do Ministério Público, inclusive no curso do processo judicial".

A Resolução 125 do Conselho Nacional de Justiça foi fruto da necessidade de se estimular, apoiar e difundir a sistematização e o aprimoramento de práticas de medição. Isso, de certa forma, fomentou a ideia e o surgimento de diversos projetos piloto nos mais diversos campos da autocomposição: mediação civil, mediação comunitária, mediação vítima-ofensor, conciliação em desapropriações, entre muitos outros. Além das práticas autocompositivas inominadas como oficinas para dependentes químicos, grupos de apoio para prevenção de violência doméstica, oficinas de habilidades emocionais para divorciandos entre outras.

Com a Resolução 125 do Conselho Nacional de Justiça, começa a se criar a necessidade de tribunais e magistrados abordarem questões como solucionadores de problemas ou como efetivos pacificador - a pergunta recorrente no Poder Judiciário deixou de ser "como devo sentenciar em tempo hábil" e passou a ser "como devo abordar essa questão para que os interesses que estão sendo pleiteados sejam realizados de modo mais eficiente, com maior satisfação do jurisdicionado e no menor prazo".

É verdade que a prática da mediação tem tido um significativo crescimento nas últimas décadas. A principal razão disso é que a sua prática, como método de resolução de controvérsias, tem demonstrado ser muito efetiva e proveitosa, denotando ser um modo menos traumatizante e aceitável pelas partes em conflito.

A mediação é mecanismo eficaz para a resolução de conflitos, uma vez que o mediador incentiva as partes a adotarem uma postura solidária, conseguindo, em muitos casos, que a relação equilibrada (conquistada no movimento de mediação) perdure, evitando a má administração dos conflitos futuros, pois o respeito e a dignidade, nesses casos, via de regra são respeitados.

No entanto, as sementes da litigiosidade continuam sendo plantadas e cultivas, o que demonstra uma certa resistência à mediação. A criação de resoluções e de novos 
códigos, por si só, não é capaz de gerar uma mudança na educação jurídica. É preciso (re)pensar a função social do Curso de Direito. É preciso (re)discutir o real função do acesso à justiça e da educação jurídica.

Segundo Alexandre Bernardino (COSTA, 2013, p.375), "o fato é que a falta de compromisso com a realidade brasileira é uma crítica dirigida há anos à Educação Jurídica. Por isso, deve-se pensar e problematizar o porquê da dificuldade de se romper com tal forma de (re)produção do conhecimento".

Ponto fundamental e crucial é o papel da extensão universitária dentro do movimento de reforma da educação jurídica, de modo a construir uma proposta em que esteja presente o constante repensar do papel do conhecimento produzido na Universidade.

\section{PODEMOS EXIGIR FRUTOS DA PACIFICAÇÃO ORIUNDOS DE SEMENTOS DO LITÍGIO.}

A expressão "acesso à justiça" é reconhecidamente de difícil definição, mas serve para duas finalidades básicas do sistema jurídico. Primeiro, o sistema deve ser igualmente acessível a todos; segundo, ele deve produzir resultados que sejam individual e socialmente justos (CAPPELLETTI, GARTH, 2002, p.8).

Um fator ponderoso da baixa performance reside na leitura exacerbada do acesso à justiça, inclusive do próprio texto constitucional que reza: "A lei não excluirá da apreciação do Poder Judiciário lesão ou ameaça a direito”. Isso tem deixado como resíduo negativo a popularizada percepção de que há uma oferta genérica, prodigalizada e incondicionada do serviço judiciário, o que não raro acaba operando como um convite ou estímulo a litigância.

A problemática reside no fato de que a cultura demandista, a crítica ao Judiciário, bem como as definições restritivas de acesso à justiça são, diariamente, propagadas nas salas de aula das Faculdades de Direito. Observa-se um ensino e uma educação jurídica atrelada ao enraizamento do problema, olvidando-se de trabalhar em cima dos caminhos, das discussões e, principalmente, das soluções. 
Será que o Judiciário é (mesmo) culpado por todos esses problemas? O conceito de jurisdição é de monopólio do Estado? Não teria o acesso à Justiça um caráter múltiplo?

Estamos, diariamente, diante de um círculo vicioso: o "Nasce, cresce, reproduz e desaparece". Nasce ouvindo que o Judiciário, ainda que moroso, é o caminho certo pra solucionar todas as lides; Cresce buscando (no campo da positivação e das leituras das normas jurídicas) esse ideal de Justiça perfeita; Reproduz (ainda na Faculdade) as mesmas críticas ao Judiciário, sem buscar, através de atividades de extensão, caminhos e soluções para os problemas do acesso à justiça; E Desaparece toda e qualquer possibilidade de efetividade da mediação como meio de solução de conflitos. Resumindo, o fruto exigido é incompatível com a semente plantada.

Essa (ainda) realidade nos leva a discussão acerca da transformação da educação jurídica. Qual o papel do Curso de Direito? Qual o papel do Professor de Direito? Qual o papel do aluno de Direito? Há, de fato, uma relação equânime entre ensino, pesquisa e extensão?

A teoria crítica pós-moderna parte do pressuposto de que o acolhimento é sempre contextualizado pelas condições que o tornam possível e de que ele só progride na medida em que transforma em sentido progressista essas condições (SOUSA SANTOS, 2007, p.32). Trata-se, portanto, da construção de um perfil de jurista que seja renovado em suas habilidades e, principalmente, sensibilizado pela prática extensionista, de modo a ser capaz de compreender a função do Direito.

No campo da mediação, encontramos, ainda, três problemas. O primeiro está ligado ao fato de que a mediação é rotulada como meio alternativo de solução de conflito, o que a torna residual e secundária diante da "forte" possibilidade de judicialização. O segundo está atrelado à carência das atividades extensionistas nas Faculdades de Direito, bem como a intensificação das práticas mediativas. Já o último problema encontra guarita na carência de acompanhamento, discussão e assessoria Jurídica às comunidades locais.

Já afirmava Darcy Ribeiro (1986, p.10) que “o saber ou a técnica, por componentes que sejam, nada significam, se não se perguntam para que e para quem existem e operam, se não se perguntam a quem servem, se não se perguntam se há convivência do sábio com o cobiçoso".

A mediação precisa (e necessita) buscar seu próprio espaço, não devendo, pois, esse meio buscar afirmação social, apenas, apostando na deficiência da justiça oficial. Até 
porque encontramos perfis diferentes: a solução judicial aponta problemas, a mediação potencializa a capacidade de compreensão dos problemas e a possibilidade de respostas mais corretas; a solução judicial impõe normas e posturas; a mediação conduz as partes a decidir o que é melhor para a continuidade da vida familiar pós-ruptura, o que justifica maior adesão dos destinatários; a decisão judicial acirra o impasse da infinita litigância enquanto a mediação procura, no consenso, diminuir a gravidade da situação fática conduzindo as partes à segurança de resoluções sugeridas pelo mediador.

Pra isso, o ensino jurídico (ainda preso aos conceitos, métodos e regras que deverão ser reproduzidos nos tribunais) precisa passar por outras maneiras de pensar e se expressar. As faculdades precisam semear essas práticas, visto que isso implicará em resultados positivos no decorrer do exercício das mais diversas carreiras jurídicas.

A Resolução 125 do Conselho Nacional de Justiça e Novo Código Processual Civil não são suficientes se não acompanhados por uma cultura que semeie (entre docentes, discentes e comunidade) a discussão e o conhecimento acerca dos frutos da mediação. O grande passo é o de semear essa educação nas faculdades e nas comunidades locais.

\section{A COLHEITA DOS BONS FRUTOS DEPENDE DOS SEUS SEMEADORES.}

O compromisso com o social é um engajamento precípuo e permanente de toda a função desempenhada pelo Estado contemporâneo, não só porque a gestão da coisa pública é feita em contemplação do atendimento ao interesse geral, mas também porque toda atividade estatal implica em alguma oneração ao patrimônio público.

O Estado-Juiz não pode, sob qualquer pretexto ou motivo, fornecer prestação jurisdicional de baixa qualidade, e, em contrapartida, o jurisdicionado tem direito a uma resposta juridicamente consistente, inclusive no tocante aos quesitos da motivação e da prolação em tempo razoável.

Um fator ponderoso dessa baixa performance reside na leitura exacerbada do acesso à justiça: "A lei não excluirá da apreciação do Poder Judiciário lesão ou ameaça a direito". Isso tem deixado como resíduo negativo a popularizada percepção de que há uma oferta genérica, prodigalizada e incondicionada do serviço judiciário, o que não raro acaba 
operando como um convite ou estímulo a litigância. Essa equivocada avaliação provoca graves efeitos colaterais, em modo de externalidades negativas.

$\mathrm{O}$ acesso à justiça deve desvestir-se dos excessos que o têm feito operar como um único e exclusivo "convite à demanda" para, realisticamente, estender-se a um "acesso" encontrado, também, nas salas de aula, nos núcleos de prática e assessorias jurídicas comunitárias, operando num renovado ambiente de ensino jurídico. Questões que as comunidades puderem solucionar através das assessorias comunitárias ou com auxílio dos núcleos de práticas jurídicas serão determinantes e satisfatórias.

O notório crescimento, quantitativo e qualitativo, dos meios alternativos se verifica em proporção inversa à perda de eficiência e prestígio do serviço estatal de distribuição da Justiça, comprometendo a credibilidade do Judiciário ao interno da coletividade.

A facilidade de acesso aos Juizados, por exemplo, acabou por retroalimentar a demanda por justiça. A criação dos Juizados não necessariamente reduz o número de demandas, podendo chegar a um crescimento desse número e a visibilidade de demandas que antes não chegavam ao Judiciário.

Dessa forma, partindo da premissa de que ambas as vertentes de distribuição de Justiça buscam objetivo comum, ou seja, a justa composição dos conflitos, então é fundamental que as duas funcionem bem.

Quanto aos meios auto e heterocompositivos ditos alternativos, devem se justificar de per si e buscar seu próprio espaço, não devendo, pois, esses outros meios buscar afirmação social apostando na deficiência da justiça oficial, num deletério jogo de soma zero.

O enfrentamento dessas questões pode ser visualizada quando se semeia o engajamento, o conhecimento, o diálogo, a extensão e a pesquisa. Para isso, necessário se faz a análise da educação jurídica e da formação do jurista que irá atuar na comunidade, à procura da melhor realização daquele direito, anteriormente estudado na Faculdade.

Um olhar crítico sobre a educação jurídica implica indagar sobre as habilidades e competências que devem ser desenvolvidas por um estudante de Direito ao longo de sua formação universitária, de modo a torná-lo mais sensível às demandas contemporâneas. Relacionar educação, ensino jurídico e contextualidade requer, antes de tudo, adotar uma 
compreensão do Direito como prática social, como algo que está em permanente construção.

A construção de uma educação jurídica, com enfoque na discussão e na prática da mediação, traz, intrinsecamente, a renovação dos perfis e habilidades dos juristas. Esperase que essa renovação possibilite a construção do amplo pensamento, formando juristas socialmente comprometidos com a defesa da cidadania, em sintonia com os desafios do seu tempo.

\section{NA ARTE DE SEMEAR, NUNCA ESTAMOS SÓS.}

Os juristas precisam, agora, reconhecer que as cortes não são a única forma de solução de conflitos a ser considerada. O "acesso" não é apenas um direito social fundamental, crescentemente reconhecido, ele é, também, necessariamente, o ponto central da moderna processualística. Seu estudo pressupõe um alargamento e aprofundamento dos objetivos e métodos da moderna ciência jurídica (CAPPELLETTI, GARTH, 2002, p.14).

A concepção contemporânea de jurisdição vai deixando de ser tão centrada no Poder - dimensão estática ligada à soberania - para se tornar inerente à função (dimensão dinâmica) que o Estado Social de Direito deve desempenhar no sentido de promover a resolução justa de conflitos. Isso leva a que esse desiderato possa ser exercido não mais em termos de monopólio estatal na distribuição da Justiça, mas consentindo outras modalidades e instâncias decisórias, ao pressuposto de que desempenhem com efetividade suas atribuições, donde o notório crescimento dos chamados meios de solução de conflitos (MANCUSO, 2013, p.65).

No Brasil, como em outros países do mundo, há vários obstáculos que impedem as pessoas de ter acesso à justiça, tais como a pobreza e a falta de cultura e informações, além da inexistência de programas e posturas oficiais a esse respeito. De que adianta, então, a garantia da inafastabilidade, se grande parte da população não consegue sequer acessar à Justiça para fazer valer seus direitos? (CARMONA, 2009, p.68). 
O ponto mais comum nas abordagens correntes sobre acesso à justiça é figurar a sua representação num movimento de busca de superação das dificuldades para penetrar nos canais formais de resolução dos conflitos (SADEK, 2001).

Nos ensinamentos de Boaventura de Sousa (SANTOS, 1993, p.114), o acesso à justiça é um fenômeno muito mais complexo do que à primeira vista pode parecer, já que para além das condicionantes econômicas, sempre óbvias, envolvem condicionantes sociais e culturais resultantes de processos de socialização e interiorização de valores dominantes muito difíceis de transformar.

O entendimento de José Geraldo (SOUSA JÚNIOR, 2009, p.160),

Se, ao limite, a partir de Boaventura de Sousa Santos e com ele, pudermos alargar o conceito de acesso à Justiça, o plano mais amplo que poderíamos lograr concebê-lo, seria, talvez, pensá-lo como um procedimento de tradução, ou seja, uma estratégia de mediação capaz de criar uma inteligibilidade mútua entre experiências possíveis edisponíveis para o reconhecimento de saberes, de culturas e de práticas sociais que formas as identidades dos sujeitos que buscam superar seus conflitos.

Observa-se que o nível restrito de acesso à justiça, portanto, se reafirma no sistema judicial. O nível mais amplo do mesmo conceito se fortalece em espaços de sociabilidade que se localizam fora ou na fronteira do sistema de justiça. Contudo, ambos os níveis se referem a uma mesma sociedade, na qual se pretende o exercício constante da democracia.

José Geraldo (SOUSA JÚNIOR, 2009, p.165), com base nos fundamentos de Roberto Lyra, afirma que

Estudar Direito implica elaborar uma nova cultura para as Faculdades e cursos jurídicos e, um dos eixos fundamentais dessa reformulação cultural tem sido, à luz das diretrizes em curso, constituir-se a uma educação jurídica uma articulação epistemológica de teoria e prática para suportar um sistema permanente de ampliação do acesso à justiça, com a abertura a temas e problemas críticos da atualidade, dando-se conta ao mesmo tempo, das possibilidades de aperfeiçoamento de novos institutos jurídicos para indicar novas alternativas para sua utilização. 
Essa nova cultura subjacente ao ensino do direito terá repercussões nas formas de recrutamento e formação dos profissionais de Direito, redirecionando a seleção com base nas habilidades essenciais para a democratização profunda do acesso à justiça. Entre essas competências, destacamos a abertura epistemológica para o pluralismo jurídico.

O desenvolvimento de um perfil não apenas técnico, mas também humanista dos agentes jurídicos em condições de promover a reflexão sobre a condição humana que contextualize o direito no seu ambiente histórico, cultural, político, existencial e afetivo; e a aptidão para distinguir entre as múltiplas demandas, as que exigem a construção de um ambiente procedimental adequado para negociação de diferenças e diminuição de desigualdades sociais (SOUSA JÚNIOR, 2009, p.167).

Segundo Alexandre Bernardino (COSTA, 2013, p.375),

O fato é que a falta de compromisso com a realidade brasileira é uma crítica dirigida há anos à Educação Jurídica. Por isso, deve-se pensar e problematizar o porquê da dificuldade de se romper com tal forma de (re)produção do conhecimento. Propõe-se explorar o papel da extensão universitária dentro do movimento de reforma da educação jurídica, de moda a construir proposta em que esteja presente o constante repensar do papel do conhecimento produzido em uma Universidade.

O que se coloca como problema básico do Judiciário hoje já não é apenas o julgar conforme a lei. Estamos diante de um quadro mais complexo. As demandas sociais são explosivas na situação brasileira e que está em cheque não é apenas o Judiciário, mas é todo o Estado.

Nas lições de Ildemar Egger (in VERONESE, 2013, p.251), a mediação funciona como uma permissão para pensar diferente, fora das canônicas posturas das origens. $\mathrm{O}$ mediador como o sujeito que funciona como ponte de reconstrução do diálogo. É válido destacar que os programas de humanização e justiça comunitária que representam uma valiosa contribuição aos processos de divulgação da cultura jurídica. Por meio desses programas, o aprendizado do Direito e de outros saberes sai das faculdades, das escolas e se instala em diferentes lugares da própria sociedade.

Mediar conflitos, portanto, requer atuar em uma situação de alteridade sem as hierarquias que opõem as práticas do social às prescrições da autoridade localizada no Estado, operando por meio do Direito adjudicado por um especialista (o juiz) a partir de 
uma pauta restrita (o código, a lei), em relação a sujeitos que não são reconhecidos em suas identidades (ainda não constituídos plenamente como seres humanos e cidadãos) e que buscam construir a sua cidadania por meio de um protagonismo que busca o direito no social. Nesse processo, que antecede e sucede o procedimento legislativo, o Direito, que não se contêm apenas no espaço estatal e dos códigos é, efetivamente, achado na rua (SÁ E SILVA, 2007, p.19).

A mediação pode tornar-se uma engrenagem fundamental na construção cidadã dos direitos humanos, através da humanização nos procedimentos de resolução de controvérsias, levando-se em conta o sentimento das partes com supremacia sobre os seus conflitos, colocando-se em primeiro plano as pessoas e seus sentimentos, visando, assim, a preservação dos relacionamentos interpessoais. Cumpre observar que a mediação ainda é considerado um recurso alternativo ao judiciário, devendo essa visão de 'secundariedade' ser modificada. (WARAT, 2001, p.89).

\section{CONCLUSÃO: POR UMA CULTURA DA CONCILIAÇÃo E MEDIAÇÃO NO SEMIÁRIDO POTIGUAR.}

A vida na sociedade contemporânea, massificada e conflitiva, impõe a consciência de que é preciso abrir algumas concessões e tolerar certos comportamentos, não havendo como como converter cada interesse contrariado ou insatisfeito numa lide judicial, sob pena de se acentuarem as animosidades e de se generalizar a conflituosidade, com repercussão no assombroso número de processos judiciais.

É preciso aceitar a inclusão, no conceito de jurisdição, de mecanismos não judiciais de solução de conflitos, permitindo, assim, uma interpretação mais próxima das finalidades na norma de inafastabilidade. Afinal, o objeto do legislador constitucional não é outro do que aquele de propiciar uma resposta adequada a qualquer ameaça ou lesão a direito.

A jurisdição estatal, nesse aspecto, precisa ser vista como um recurso final, uma maneira de obter uma palavra final acerca de determinada controvérsia. A alternativa judicial deixa de significar, entretanto, a saída melhor ou necessária de solucionar uma 
controvérsia. O modo judicial de solução de conflitos deve ser visto como uma das formas dentro de um universo de alternativas parcial ou totalmente direcionadas aos mesmos fins.

Com a crescente difusão dos chamados meios consensuais de resolução de controvérsias, tornou-se imperiosa a necessidade de criar parâmetros e regras específicas que viessem normatizar a utilização de tais institutos. No Brasil, os mais emblemáticos diplomas normativos a tratar sobre a conciliação e a mediação são a Resolução $n^{o}$ 125/2010 do Conselho Nacional de Justiça, a Lei 13.140/15 (a chamada Lei de Mediação) e a Lei no 13.105/15, que instituiu o novo Código de Processo Civil.

A política de crescimento físico do Judiciário, sobre não resolver o problema do excesso de demanda, ao final se traduz em frustração aos jurisdicionados, que, ou se resignam ao acompanhar o lento e estressante trâmite dos processos, ou aceitam antecipar seu término, não raro firmando acordos insatisfatórios ou mesmo ruinosos. E nesse contexto, a função judicial do Estado sai como: lenta, onerosa, imprevisível, massificada e "injusta".

A concepção de um serviço de distribuição de justiça monopolizado pelo Estado, acompanhado de uma concepção prodigalizada e incondicionada de prestação judiciária, deve ser gradualmente afastada, até porque reporta a uma realidade judiciária defasada, sem mais correspondência com a atualidade, revelando-se irrealista e atécnica.

Não há como negar que o chamado monopólio estatal da distribuição da Justiça não guarda aderência à realidade atual, devendo ser devidamente revistada e contextualizada para se compatibilizar com as novas necessidades e interesses emergentes na contemporânea sociedade massificada e conflitiva.

A função judicial do Estado não é imposta aos jurisdicionados, mas na verdade é uma prestação ofertada a quem dela necessite, em face de controvérsias insuscetíveis de composição entre os diretamente interessados.

O Projeto "Das Sementes aos Frutos" é desenvolvido pelo Curso de Direito da Universidade Federal Rural do Semiárido e tem como objetivo acompanhar e avaliar, no campo da medição, a (re)estruturação da educação jurídica no semiárido potiguar, com ênfase nas quatro cidades que abarcam os campi da UFERSA: Mossoró, Angicos, Pau dos Ferros e Caraúbas. 
As atividades do projeto são desenvolvidas nas salas de aula, nos Núcleos de Práticas Jurídicas da UFERSA e de outros cursos, além das comunidades do semiárido potiguar (principalmente as vinculadas aos campi da UFERSA: Mossoró, Caraúbas, Pau dos Ferros e Angicos).

Os alunos do Curso de Direito estão diretamente vinculados ao projeto. Eles passam a aprender, desde cedo, a teoria e a prática da medição. Análise de textos, simulações, práticas, análise de casos concretos, apresentação de textos e atendimentos às comunidades são as nossas grandes e verdadeiras sementes, responsáveis pelos frutos futuros.

Somado a tudo isso, o projeto conta com a parceria com o Tribunal de Justiça do Rio Grande do Norte, onde os alunos passam a atuar nas questões, nos casos, nos conflitos que chegam ao Fórum da cidade de Mossoró e que são encaminhados para o Núcleo de Práticas Jurídicas da UFERSA.

Já está programada, também, o início das visitas em comunidades, associações e escolas. Tudo isso de forma organizada, através de cartilhas, com a finalidade de transmitir a cultura da pacificação para os mais diversos setores da comunidade do semiárido potiguar.

Percebe-se que é urgente a criação de uma cultura da da conciliação e mediação. Uma cultura atrelada a um maior comprometimento com a educação jurídica, através da sala de aula e dos núcleos de práticas jurídicas, com a formação universitária e com o engajamento comunitário. Somente através das boas sementes é que poderemos colher os bons frutos.

\section{BIBLIOGRAFIA BÁSICA}

APOSTOlOVA, Bistra. Perfil e Habilidades do Jurista: Razão e Sensibilidade. Notícia do Direito Brasileiro, n 5. Brasília: Faculdade de Direito da UnB, 1999.

ADEODATO, João Maurício. Formação Jurídica Docente: Conhecimento, Atitudes, Operacionalização. OAB Ensino Jurídico. Balanço de Uma Experiência. Brasília: Conselho Federal da OAB, 2000. 
AGUIAR, Roberto A. R. de. Habilidades. Ensino Jurídico e Contemporaneidade. Rio de Janeiro: DP\&A, 2004.

CARMONA, Carlos Alberto. Arbitragem e Processo. São Paulo: Atlas, 2009.

CAPPELleTt, M.; GARTH, B. Acesso à Justiça. Porto Alegre: Sergio Fabris, 2002.

COSTA, Alexandre Bernardino (Org). Direito Vivo: Leituras sobre constitucionalismo, construção social e educação a partir do Direito Achado na Rua. Vol.1. Brasília: UnB, 2013.

EGGER, Ildemar. A mediação como instrumento de fraternidade. In VERONESE, J. R. Petry; OLIVEIRA, Olga M. Boshi A. Direito e Fraternidade. Rio de Janeiro: Lumen Juris, 2013.

FARIA, J. E. Direitos Humanos, Direitos Sociais e Justiça. São Paulo: Malheiros, 2010. GRINOVER, Ada Pellegrini. Projeto de lei sobre mediação e outros meios de pacificação. São Paulo: DPJ, 2006.

. Os fundamentos da Justiça conciliativa. Revista de Arbitragem e Mediação, n.14, jul-set 2007, p.16-21.

LYRA FILHO, Roberto. O que é Direito?. 17. ed. São Paulo: Brasiliense, 2007.

MANCUSO, Rodolfo de Camargo. A resolução dos conflitos e a função judicial no contemporâneo Estado de Direito. 2ed. São Paulo: Revista dos Tribunais, 2014.

Acesso à Justiça: Condicionantes legítimas e ilegítimas. São Paulo, Revista dos Tribunais, 2012.

MOREIRA, José Carlos Barbosa. O futuro da Justiça: Alguns mitos. Temas de Direito Processual. $8^{\mathrm{a}}$ série. São Paulo: Saraiva, 2004.

NALINI, José Renato. A democratização da administração dos Tribunais. IN RENAULT, Sérgio Rabello Tamm (Coord.). Reforma do Judiciário. São Paulo: Saraiva, 2005.

RIBEIRO, Darcy. Universidade pra quê? Brasília: Universidade de Brasília, 1986.

SÁ E SILVA, Fábio C. M. Ensino Jurídico: A Descoberta de Novos Saberes para a Democratização do Direito e da Sociedade. Porto Alegre: Sergio Antonio Fabris Editor, 2007.

SADEK, Maria Teresa. A efetividade de direitos e acesso à Justiça. IN RENAULT, Sérgio Rabello Tamm (Coord.). Reforma do Judiciário. São Paulo: Saraiva, 2005.

Stiftung, 2001.

Acesso à Justiça. Pesquisas,n.23. São Paulo: Konrad Adenauer- 
SALES, Lilia Maia de M. Justiça e Mediação de conflitos. Belo Horizonte: Del Rey, 2003.

SANTOS, Boaventura de Sousa. Introdução à Sociologia da Administração da Justiça, in José Geraldo de Sousa Júnior; Roberto A. R. de Aguiar (orgs.). Introdução Crítica ao Direito do Trabalho. Série O Direito Achado na Rua, vol. 2. Brasília: CEAD/NEP, 1993.

. Os caminhos do cosmopolitismo multicultural. v.3. Rio de Janeiro: Civilização Brasileira, 2003.

(org). Conhecimento Prudente para uma Vida Decente. 'Um discurso sobre as ciências’ revisitado. São Paulo: Cortez, 2004.

A Universidade no Século XXI. Para uma reforma democrática e emancipatória da Universidade. São Paulo: Cortez, 2007.

. Pluralismo jurídico os novos caminhos da contemporaneidade. São

Paulo: Saraiva, 2010.

SILVA, Eduardo Silva da. Meios complementares de acesso à Justiça: Fundamentos para uma teoria geral. Revista Processo e Constituição. Faculdade de Direito da Universidade Federal do Rio Grande do Sul, n.1, dez. 2004, p. 163-192.

SOUSA JÚNIOR, José Geraldo de. Direito como Liberdade: O Direito Achado na Rua e experiências populares emancipatórias de criação do Direito. Brasília: UnB, 2009. http://repositorio.unb.br/bitstream/10482/1401/1/TESE_2008_JoseGeraldoSJunior.pdf Acesso em 04.03.2015.

. Ensino do Direito, Núcleos de Prática e de Assessoria Jurídica. Belo Horizonte: Veredas do Direito, v. 3, 2006, p. 123-144.

- Ensino Jurídico: Conhecimento do Direito e suas Formas Sociais de Produção, in José Geraldo de Sousa Júnior. Sociologia Jurídica: Condições Sociais e Possibilidades Teóricas. Porto Alegre: Sergio Antonio Fabris Editor, 2002.

VERONESE, Josiane Rose Petry; OLIVEIRA, Olga Maria Boshi Aguiar. Direitos na Pós-Modernidade: A fraternidade em questão. Florianópolis: Fundação Boiteux, 2011.

. Direito e Fraternidade. Rio de Janeiro: Lumen Juris, 2013.

WATANABE, Kazuo. Cultura da sentença e cultura da pacificação. In: Yarshell, Flávio Luiz; MORAES, Maurício Zanoide de. (Coord.). Estudos em homenagem à professora Ada Pellegrini Grinover. São Paulo: DPJ, 2009.

WARAT, Luis Alberto. O ofício do mediador. Vol. I. Florianópolis: Habitus, 2001.

Funjab, 2004.

. Epistemologia e Ensino do Direito. O sonho acabou. Florianópolis: 
Surfando na Pororoca: O Ofício do Mediador. Florianópolis: Fundação Boiteux, 2004.

WOLKMER, Antônio Carlos. Pluralismo Jurídico: Fundamentos de uma nova cultura no Direito. 3ed. São Paulo: Alfa-Ômega, 2001. 